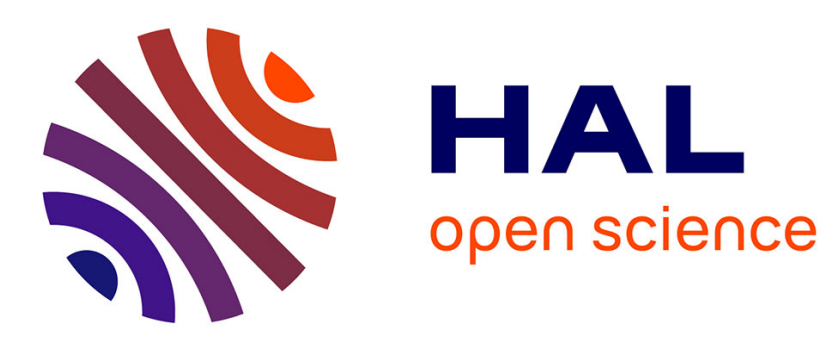

\title{
Investigating the role of deposition on the size distribution of near-surface dust flux during erosion events
}

Royston Fernandes, Sylvain Dupont, Eric Lamaud

\section{To cite this version:}

Royston Fernandes, Sylvain Dupont, Eric Lamaud. Investigating the role of deposition on the size distribution of near-surface dust flux during erosion events. Aeolian Research, 2019, 37, pp.32-43. 10.1016/j.aeolia.2019.02.002 . hal-02055226

\section{HAL Id: hal-02055226 \\ https://hal.science/hal-02055226}

Submitted on 22 Oct 2021

HAL is a multi-disciplinary open access archive for the deposit and dissemination of scientific research documents, whether they are published or not. The documents may come from teaching and research institutions in France or abroad, or from public or private research centers.
L'archive ouverte pluridisciplinaire HAL, est destinée au dépôt et à la diffusion de documents scientifiques de niveau recherche, publiés ou non, émanant des établissements d'enseignement et de recherche français ou étrangers, des laboratoires publics ou privés.

\section{(c) (1) $\$$}

Distributed under a Creative Commons Attribution - NonCommerciall 4.0 International 


\section{Investigating the role of deposition on the size distribution of near-surface dust flux during erosion events}

\section{Abstract}

Predicting the particle-size-distribution (PSD) of near-surface turbulent dust flux $\left(F_{w c}\right)$ is a key issue for estimating the size of atmospheric mineral dust. Existing dust emission schemes differ in their parametrization of the emitted dust $\left(F_{e m i}\right)$ PSD, defining differently the surface 9 inter-particle cohesive force and the influence of wind intensity. Moreover, these schemes have 10 often been validated-fitted against field measurements, assuming PSD similarity between $F_{w c}$ and $F_{e m i}$. Here, we investigate numerically the main factors influencing $F_{w c}-$ PSD during erosion events. To this effect, we developed a 1D dust-dispersal model. After evaluating the model against published results, it is shown that $F_{w c}$-PSD is influenced by both deposition and $F_{e m i^{-}}$ PSD. This latter one is shaped by the inter-particle cohesive bond exponent and the surface dust PSD. A time-to-space conversion of the dust flux variations reveals an increasing enrichment of $F_{w c}$ in small particles compared to $F_{e m i}$. This enrichment remains lower than a few percent of the total dust flux (in number) for fetch lower than $100 \mathrm{~m}$, but it can rise to more than $10 \%$ for fetch longer than $1 \mathrm{~km}$. This fetch dependence of $F_{w c}$-PSD is explained by the slow deposition of particles having the lowest deposition velocities. Importantly, this difference between $F_{w c}$ and $F_{e m i}$ PSDs is accentuated with wind intensity, with $F_{e m i}$-PSD dominated by particles with large deposition velocities, and in presence of a large-scale background dust concentration. The role played by the deposition process in shaping the $F_{w c}$-PSD should be considered when evaluating dust emission schemes against near-surface field measurements.

Keywords: Dust flux, Size distribution, Dust emission, Dust deposition, Deposition velocity

\footnotetext{
*Corresponding Author

Email address: royston. fernandes@inra.fr (Royston Fernandes) 


\section{Investigating the role of deposition on the size distribution of near-surface dust flux during erosion events}

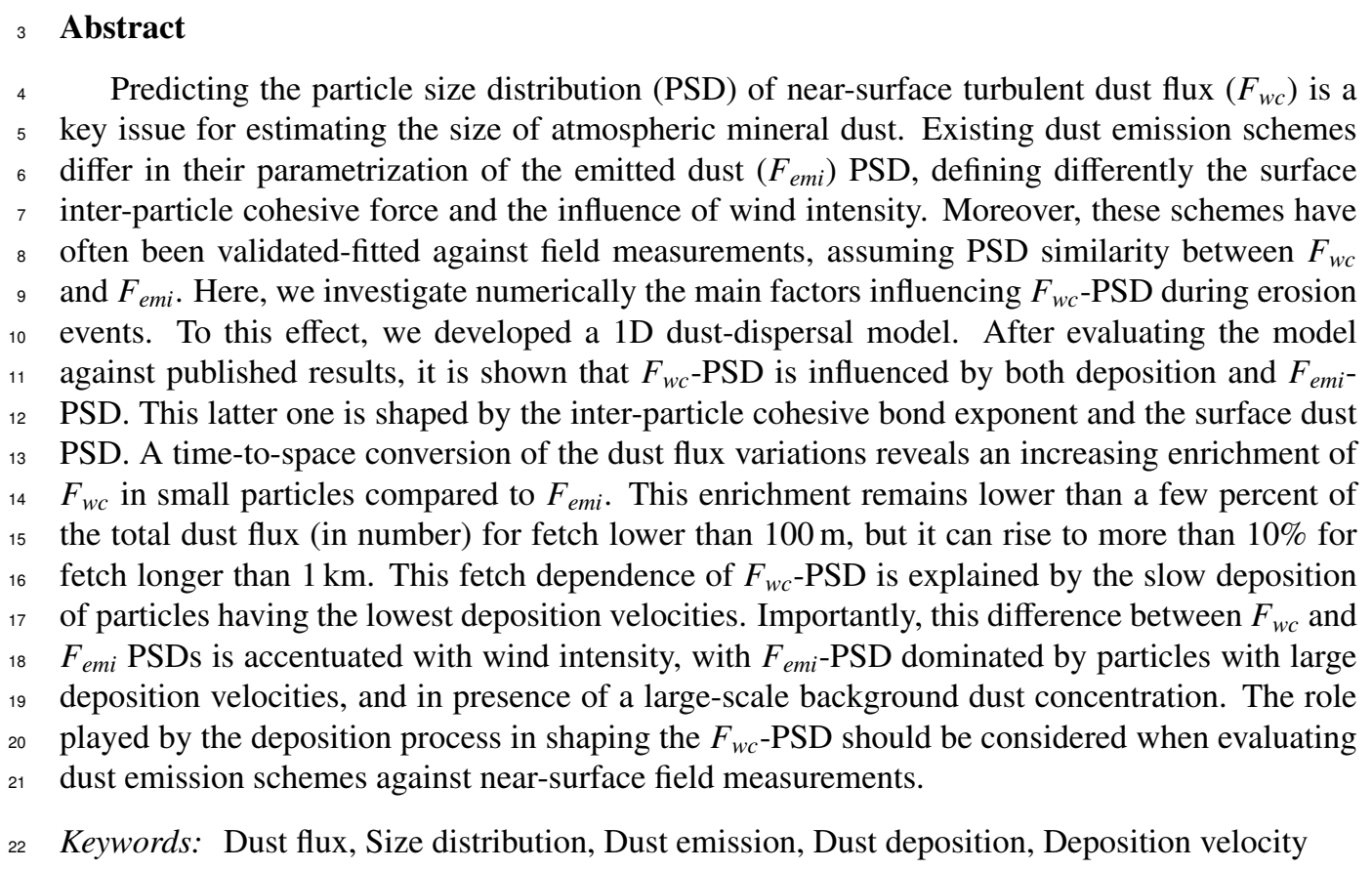

\section{1. Introduction}

Mineral dust aerosols are a fundamental component of the Earth system. They refer to fine suspended soil particles (diameter $<20 \mu \mathrm{m}$ ) released by strong winds in regions with erodible soils (Knippertz and Stuut, 2014). The life-cycle of airborne dust involves three stages: (1) the release from the surface, (2) the transport in the atmosphere over long distances by turbulent diffusion and against gravitational sedimentation, and (3) the deposition back on to the surface. These three stages shape the particle size distribution (PSD) of the near-surface dust flux. Interest in understanding the PSD of dust flux is fueled by the impact of the aerosol size on different Earth processes (e.g., Mahowald et al., 2014) such as weather and climate (e.g., Claquin et al., 2003; Otto et al., 2007), ecosystem nutrient supply (e.g., Swap et al., 1992; Knippertz and Stuut, 2014), and human health (e.g., Weuve et al., 2012; Derbyshire, 2007).

The entrainment of dust particles from the surface is driven by sandblasting (e.g., Shao et al., 1993; Marticorena and Bergametti, 1995; Alfaro et al., 1997; Shao and Lu, 2000; Alfaro and Gomes, 2001; Shao, 2001; Kok, 2011b), and, to a lesser extent, by aerodynamic forces (e.g., 
Greeley and Iversen, 1987). Under saltation, dust particles are released when sufficient energy from an impacting saltator is available to break surface inter-particle cohesive bonds $(E)$. In dust emission schemes, saltation is considered as the necessary process for releasing dust. The dust flux is, therefore, often a function of the saltation flux (e.g., Shao et al., 1993; Marticorena and Bergametti, 1995; Alfaro and Gomes, 2001; Shao, 2001; Kok, 2011b; Kok et al., 2014). While the link between saltation and dust fluxes is well established, the processes shaping the PSD of the dust flux remain unclear.

In dust emission schemes, the emitted dust PSD is usually influenced by (1) the surface interparticle cohesive bond, (2) the soil PSD, and/or (3) the wind intensity, as reviewed below.

The surface inter-particle cohesive bond $(E)$. The parametrization of $E$ differs from one scheme to the other. In Shao et al. (1996), $E$ was assumed proportional to the drag force acting on the particle multiplied by some length scale, leading to $E \propto d_{p}^{3}$, where $d_{p}$ is the diameter of the released dust. Later, Shao (2001) and Kok et al. (2014) related $E$ to the van der Waals bond at the surface, leading to $E \propto d_{p}^{2}$. Then Shao (2008) suggested an ensemble surface cohesive bond propertional to the particle size, leading to $E \propto d_{p}$ The same was considered by Kok et al. (2014) . Differently, Alfaro and Gomes (2001) proposed an inverse relationship between $E$ and the particle size, $E \propto d_{p}^{-0.018}$ (deduced from their Table 1). This allowed them to reproduce Alfaro et al. (1997) wind-tunnel experiment where finer particles were released under higher wind conditions, i.e., higher energy of the impacting saltators.

The soil particle size distribution. The influence of the soil PSD on the dust flux changes according to the dust emission schemes. Marticorena and Bergametti (1995) related the dust flux PSD to the percentage of clay present in the soil, i.e., percentage of particles lower than $3.9 \mu \mathrm{m}$. In Alfaro and Gomes (2001), the emission of dust is derived from a distribution with three lognormal modes, where the contribution of each mode depends on the strength of the inter-particle cohesive bond and on the wind intensity. In Shao (2001), the emission of dust is derived from a distribution with two modestwo PSDs, minimally and fully disaggregated modesdistributions, with an adjustable weight parameter to determine their relative contribution. Kok (2011b) suggested that aggregates behave like brittle materials where the emitted dust PSD is determined by patterns in which cracks nucleate and propagate. A compilation of published flux measurements in Kok et al. (2012) indicated a limited effect of soil texture on the observed dust flux PSD. This insensitivity of the dust flux PSD to the soil granulometry was also suggested in Reid et al. (2008).

The wind intensity. The influence of the wind intensity on the emitted dust PSD remains unclear. On one hand, Shao (2001) and Alfaro and Gomes (2001) considered an enrichment of the dust flux in smaller particles with increasing wind intensity, due to the stronger disintegration of aggregates by adjusting their weight parameters as a function of atmospheric forcing. On the other hand, Kok (2011b) proposed the independence of the emitted dust PSD to the wind intensity, deduced from a compilation of field measurements showing negligible differences of the dust flux PSD under various wind conditions (Kok, 2011a).

The definition of the dust flux simulated by dust emission schemes remained also vague in regard to the measured fluxes used to evaluate-fit them (e.g., Shao et al., 1993; Marticorena and Bergametti, 1995; Shao, 2001; Alfaro and Gomes, 2001; Kok et al., 2014). The dust fluxes simulated by these schemes are most likely the the surface emitted dust fluxes at the surface since these schemes do not explicitly simulate turbulence nor consider the effect of deposition during emission. However, these simulated fluxes have most often been evaluated-fitted against field measurements performed well above the surface (several meters) and at various distances from the upwind border of the dust source area, i.e. fetch sizes ranging from $100 \mathrm{~m}$ to 
more than 10 km (e.g., Gillette, 1977; Gomes et al., 2003; Gillies and Berkofsky, 2004; Zobeck and Scott Van Pelt, 2006; Fratini et al., 2007; Sow et al., 2009). This implies an hypothesis of PSD similarity between near-surface and surface fluxes, and thus a negligible impact of the both the gravitational settling of the largest particles and the particle surface deposition across all sizes. Only Shao et al. (2011) applied a correction to the measured dust flux to account for the graviational settling but without considering the full deposition process. Dupont et al. (2015) obtained from large-eddy simulations (LES) of aeolian erosion events an increasing difference in PSD with time between near-surface dust flux and emission flux as a result of a first particle sorting through turbulence diffusion, gravitational settling, and more importantly surface deposition. Their results were, however, limited to three particle sizes $(1.40,6.70$ and $14.20 \mu \mathrm{m})$ and to one soil PSD with an equiprobable emission of the three dust particle sizes, limiting a more general view of the impact of dust deposition on the near-surface dust flux PSD according to the soil PSD. Interestingly, by converting the erosion duration of their simulations into a fetch size, their results mean that the difference in PSD between near-surface dust flux and emission flux should increase with the fetch. A quantification of this difference according to the fetch size and the soil PSD would benefit to the erosion community.

The goal of the present study is twofold: (1) investigate the role of deposition in shaping the PSD of near-surface dust flux during erosion events, and, more generally, (2) investigate the sensitivity of the PSD of near-surface dust flux to the surface inter-particle cohesive bond, the PSD of available dust at the surface, the wind intensity, and the fetch length. To that purpose we extend the initial study of Dupont et al. (2015) by considering (1) dust particles ranging from 0.1 to $16 \mu \mathrm{m}$, (2) various soil PSDs, and (3) the influence of the inter-particle cohesive bond exponent $(\beta)$ on the emitted dust flux PSD. Because the LES approach used in Dupont et al. (2015) was too time consuming for performing such a detailed sensitivity analysis, we developed for this analysis a simple one-dimensional (1D) physically-based dust dispersal model, accounting for dust emission, transport, and deposition in the atmospheric surface boundary layer. After evaluating the model against published dust flux behaviors, the model is used to study the sensitivity of the PSD of the near-surface dust flux.

In this study, the near-surface dust flux will refer to the vertical turbulent-diffusive flux $\left(F_{w c}\right)$ at several meters above the surface. It corresponds to the amount of particles transported away from the surface by the flow turbulence. This flux results from a balance between the emission $\left(F_{\text {emi }}\right)$ and deposition $\left(F_{\text {dep }}\right)$ fluxes, the storing rate of particles in the air, and the gravitational settling flux $\left(F_{\text {sed }}\right)$ due to particle weight. Importantly, $F_{w c}$ does not include $F_{\text {sed }}$ and it is not equivalent to the dust emission flux at the surface $\left(F_{\text {emi }}\right)$. See Table 1 for a summary of the flux notations used in this paper.

\section{One-dimensional dust-dispersal model}

A simple 1D dust-dispersal model was developed to simulate the whole dust life-cycle in a column of air representative of the atmospheric surface boundary layer above an infinite bare erodible surface under neutral thermal stratification (Fig. 1). The model accounts for (1) dust emission through sandblasting, based on an energy budget linking the surface cohesive forces to the dust particle size, (2) dust turbulent transport within the surface boundary layer, and (3) dust deposition at the surface. 


\subsection{Wind}

The wind intensity is quantified through the friction velocity $\left(u_{*}\right)$, which is related to the turbulent flow shear stress $(\tau)$ induced by the surface:

$$
u_{*}=\sqrt{\tau / \rho_{a}},
$$

where $\rho_{a}$ is the air density. The shear stress quantifies the momentum flux absorbed by the surface. Above an homogeneous surface, $\tau$ is constant with height within the surface boundary layer. The similarity theory leads to the well-known logarithmic velocity profile expressed as:

$$
u(z)=\frac{u_{*}}{\kappa} \ln \left(\frac{z}{z_{0}}\right)
$$

where $z$ is the vertical coordinate, $z_{0}$ the surface roughness length, and $\kappa$ the von Karman constant $(=0.40)$.

In the presence of saltation, the total shear stress $(\tau)$ is partitioned within the saltation layer between the momentum flux aborbed by the surface and that absorbed by the saltators. The absorption of momentum by the saltators modifies the wind profile. This was accounted for in Raupach (1991) as:

$$
u(z)=\frac{u_{*}}{\kappa}\left[\ln \left(\frac{z}{z_{0}}\right)+(1-\sqrt{r})\left[\gamma+\ln \left(\frac{z_{0}}{H_{s}}\right)+E\left(\frac{z}{H_{s}}\right)\right]\right],
$$

where $H_{s}=0.3969 u_{*}^{2} / 2 g$ is the average height of the saltation layer with $g$ the gravitational acceleration, $r=u_{*, t}^{2} / u_{*}^{2}$ with $u_{*, t}$ the threshold friction velocity above which saltation starts, $\gamma=0.577216$ is the Eulers constant, and $E(x)=\int_{x}^{\infty} \exp (-t) / t d t$. Above the saltation layer, this modification of the wind profile due to saltation is equivalent to replacing $z_{0}$ in Equation 2 by a saltation roughness length $z_{0 s}=\left[H_{s} \exp (-\gamma)\right]^{(1-\sqrt{r})} z_{0}^{\sqrt{r}}$ (Raupach, 1991).

Unlike saltating particles, the relatively small volume fraction of dust particles has negligible effect on the flow field.

\subsection{Dust transport}

An Eulerian approach was used to describe the turbulent transport of dust particles in the atmospheric surface layer. Here, dust particles were assumed spherical, non magnetic, and electrically neutral. The size range of dust particles is divided into $n_{b}$ bins, each bin being characterized by a mean particle diameter $d_{b}$. Hence, the conservation equation of the dust concentration $c_{b}$ of the bth bin is given by:

$$
\frac{\partial c_{b}(z, t)}{\partial t}=-\frac{\partial F_{w c, b}(z, t)}{\partial z}+v_{s, b} \frac{\partial c_{b}(z, t)}{\partial z}
$$

where $t$ is time, $F_{w c, b}$ is the dust turbulent-diffusive flux of the bth size bin, $v_{s, b}$ is the settling velocity of the particles of the bth size bin given as $v_{s, b}=\rho_{p} g d_{b}^{2} C_{c} /\left(18 \rho_{a} v\right)$, where $\rho_{p}$ is the dust particle density, $C_{c}$ is the Cunningham slip correction factor, and $v$ is the kinematic viscosity of air (Seinfeld and Pandis, 1998). Equation 4 means that the dust concentration variation in a grid cell results from a balance between incoming and outgoing turbulent-diffusive $\left(F_{w c, b}\right)$ and gravitational settling $\left(F_{s e d, b}=v_{s, b} c_{b}\right)$ fluxes due to turbulent motions and particle weight, respectively. 
The turbulent-diffusive dust flux is simply estimated from a flux-gradient relationship:

$$
F_{w c, b}(z, t)=-K_{d} \frac{\partial c_{b}(z, t)}{\partial z},
$$

where $K_{d}=\kappa z u_{*}\left[1-(1-\sqrt{r}) \exp \left(-z / H_{s}\right)\right]$ is the dust eddy diffusivity assuming similarity in turbulent transport between momentum and dust particles (Gillette et al., 1972). This expression of $K_{d}$ converges to its surface layer value $\kappa z u_{*}$ above the saltation layer (Raupach, 1991).

At the surface, the total dust flux $\left(F_{t o t}\right)$ accounting for both turbulent-diffusive and gravitational settling fluxes, is expressed as:

$$
F_{t o t, b}^{\text {surf }}(t)=F_{\text {emi,b }}(t)-F_{\text {dep }, b}(t),
$$

where $F_{e m i, b}$ and $F_{d e p, b}$ are the emission and deposition fluxes at the surface of dust particles of the bth bin, respectively (Fig. 1).

\subsection{Saltation}

Saltating particles are characterized by a size distribution $p_{s}$ whose diameters range from $D_{S 1}$ to $D_{S 2}$. The total saltation flux is the integration of the saltation flux of all particle sizes according to $p_{s}$ :

$$
Q_{t o t}=\int_{D_{S 1}}^{D_{S 2}} Q(D) p_{s}(D) \delta D,
$$

where the saltation flux $Q(D)$ of particles of diameter $D$ is estimated from White (1979) as follows:

$$
Q(D)=2.61 \frac{\rho_{a}}{g}\left(1+\frac{u_{*, t}(D)}{u_{*}}\right)\left(1-\left(\frac{u_{*, t}(D)}{u_{*}}\right)^{2}\right) u_{*}^{3},
$$

where $u_{*, t}(D)$ is the threshold friction velocity deduced from Marticorena and Bergametti (1995).

On average, the kinetic energy of the saltating particles of diameter $D$ impacting the surface is:

$$
E_{i m p, D}=\frac{1}{2} m_{i m p} v_{i m p}^{2}
$$

where $m_{\text {imp }}=\rho_{p} \pi D^{3} / 6$ is the particle mass, and $v_{i m p}$ is the velocity of the impacting saltator. In a first order approximation, $v_{i m p}$ is estimated as $v_{i m p}=5 u_{*, t}(D)$ (Kok et al., 2014).

Using a probabilistic approach as often used in splash schemes, the kinetic energy of impacting saltators $\left(E_{i m p}\right)$ is distributed between the energy used for saltator rebound (fraction $\left.\epsilon_{r e b}\right)$, the energy used for ejecting new saltators (fraction $\epsilon_{e j}$ ), and the energy lost to the surface (fraction $\left.\epsilon_{f r}\right)$, such as:

$$
\epsilon_{r e b}+\epsilon_{e j}+\epsilon_{f r}=1 \text {. }
$$

Here, $\epsilon_{r e b}=2 \gamma^{2} P_{r e b}$, where $P_{r e b}$ is the rebound probability (Anderson and Hallet, 1986) and $\gamma=0.55$ (Rice et al., 1995); and $\epsilon_{f r}=0.96\left(1-\epsilon_{r e b}\right)$ (Ammi et al., 2009).

This energy distribution at the surface during the saltator impact does not account for the energy fraction used for releasing dust particles from sandblasting. We hypothesized that the energy for dust emission is a fraction $\epsilon_{d}$ of the energy lost to the surface $\left(\epsilon_{f r} E_{i m p, D}\right)$. 


\subsection{Dust emission}

At the surface, dust particles lie on larger sand grains, surrounded by other dust grains, forming aggregates. A particle in this system experiences short-range dielectric attractive forces known as van der Waals forces due to inter-particle interactions (dust-dust particles or dustsand particles). Estimating the van der Waals forces between two spherical particles in contact is simple but it becomes much more complex when it comes to estimate the cohesive forces of particles in an aggregate (Shao, 2001). This explains the various parametrizations proposed in the literature for the inter-particle cohesive forces as mentioned in the introduction. Overall, these parametrizations express the inter-particle cohesive bond as a function of the dust particle diameter:

$$
E_{c o h, b}=A d_{b}^{\beta},
$$

where $\beta$ can be referred to as the inter-particle cohesive bond exponent defining the relationship between the dust particle diameter and the cohesive bond, and $A$ is a constant. In existing dust emission schemes, $\beta$ varies from -0.018 to +3 as reviewed in the introduction section.

The number of dust particles of bin $b$ released by an impacting saltator of size $D$ is defined as the ratio between the available energy for releasing dust and the energy required to eject one dust particle:

$$
N_{e m i, b}=\frac{\epsilon_{d} \epsilon_{f r} E_{i m p, D}}{A d_{b}^{\beta}},
$$

where $\epsilon_{d}$ is the fraction of the energy lost to the surface by the impacting saltator $\left(\epsilon_{f r} E_{i m p, D}\right)$ that is used to release dust. Equation 12 can be rewritten as:

$$
N_{e m i, b}=\alpha \frac{\epsilon_{f r} E_{i m p, D}}{d_{b}^{\beta}},
$$

where $\alpha$ is the dust emission coefficient resuming the two unknown constants $\epsilon_{d}$ and $A$.

Hence, the emission dust flux at the surface of the bth bin is:

$$
F_{e m i, b}=\zeta_{d}\left(d_{b}, u_{*}\right) p_{d}\left(d_{b}\right) \int_{D_{S 1}}^{D_{S 2}} N_{e m i, b}(D) \frac{Q(D)}{l(D)} p_{s}(D) \delta D,
$$

where $p_{d}\left(d_{b}\right)$ is the proportion of dust particles from the bth bin available at the surface, $Q / l$ represents the vertical flux of saltating particles or in other words the flux of impacting saltators at the surface, with $l$ the average hop length of the saltating particles. Here, $l$ was simply deduced as the maximum horizontal distance traveled by a projectile launched with a lift-off velocity $V_{e j}$ and a lift-off angle $\theta_{e j}: l=V_{e j}^{2} \sin \left(2 \theta_{e j}\right) / g$. We chose $V_{e j}=0.63 u_{*}$ and $\theta_{e j}=50^{\circ}$ (Shao, 2008). The coefficient $\zeta_{d}\left(d_{b}, u_{*}\right)$ accounts for the modification of the size distribution of emitted dust due to the enhancement of aggregate disintegration with wind speed as proposed by Alfaro et al. (1997). Unless otherwise specified, $\zeta_{d}\left(d_{b}, u_{*}\right)=1$ in our simulations, implying the size distribution of the emission dust flux is independent of the wind intensity.

\subsection{Dust Deposition}

Dust deposition on soil occurs only through dry deposition accounting for gravitational settling, turbulent mixing, and brownian diffusion (e.g., Seinfeld and Pandis, 1998). Hence, the deposition flux of dust particles from the $b$ th bin is:

$$
\begin{gathered}
F_{d e p, b}=v_{d e p, b} c_{b}^{\text {surf }}, \\
6
\end{gathered}
$$


where $c_{b}^{\text {surf }}$ is the dust concentration close to the surface (middle of the first grid cell, see Fig. 1 ), and $v_{d e p, b}$ is the particle dry deposition velocity that is classically parameterized as a set of resistances:

$$
v_{d e p, b}=\frac{1}{R_{a}+R_{b}+R_{a} R_{b} v_{s, b}}+v_{s, b},
$$

where $R_{a}=\log \left(z_{s} / z_{0 s}\right) /\left(\kappa u_{*}\right)$ is the aerodynamic resistance accounting for turbulent transfer near the surface $\left(z_{s}\right.$ is the middle of the first grid cell) with $z_{0 s}$ the saltation-layer roughness length estimated as per Raupach (1991); $R_{b}=\left[u_{*}\left(S_{c}^{-2 / 3}+10^{-3 / S_{t}}\right)\right]^{-1}$ is the quasi-laminar resistance accounting for brownian diffusion and inertial impaction on particles. Here, $S_{c}=v / D_{g}$ is the Schmidt number, $D_{g}=k_{b} T C_{c} /\left(3 \pi \rho_{p} v d_{b}\right)$ is the brownian diffusivity, with $k_{b}$ the Boltzman constant, and $T$ the air temperature, set to $27^{\circ} \mathrm{C}$ in this study. $S_{t}=u_{*}^{2} v_{s, b} /(g v)$ is the Stokes number.

Fig. 2 presents the variation of the deposition velocity with the dust particle size for different wind intensities. The deposition velocity exhibits a minimum for particles around 0.5 to $1 \mu \mathrm{m}$ in diameter. With increasing wind intensity, the deposition velocity increases, especially for the largest particles, due to the larger decrease of $R_{b}$ with increasing particle size.

\subsection{Simulation configurations}

The computational domain was meshed along the vertical using a stretched grid from the surface to the top of the domain. The grid size was varying from $\Delta \mathrm{z}_{\min }=0.01 \mathrm{~m}$ at the surface to $\Delta \mathrm{z}_{\max }=0.24 \mathrm{~m}$ at the top (Fig. 1). This mesh ensures a grid resolution fine enough to simulate exchanges close to the surface (where particle concentration is high), while reducing the computational time by considering larger grid cells for exchanges farther away. Unless otherwise specified, the total domain height was $200 \mathrm{~m}$ corresponding to the approximate depth of the atmospheric surface layer under neutral thermal stratification.

The dust conservation equation (Eq. 4) was solved using the Crank-Nicolson method (Crank and Nicolson, 1947):

$$
\frac{c_{b}^{t+\Delta t}-c_{b}^{t}}{\Delta t}=\frac{1}{2}\left[F_{i}^{t+\Delta t}\left(c_{b}, z, t+\Delta t, \frac{\partial c_{b}}{\partial z}, \frac{\partial^{2} c_{b}}{\partial z^{2}}\right)+F_{i}^{t}\left(c_{b}, z, t, \frac{\partial c_{b}}{\partial z}, \frac{\partial^{2} c_{b}}{\partial z^{2}}\right)\right],
$$

where $\Delta t=0.01 \mathrm{~s}$ is the time step and $F_{i}^{t}$ is the right-hand side term of Eq. 4 at time $t$. A Neuman boundary condition was applied at the top of the domain $\left(\partial c_{b} / \partial z=0\right)$. This resolution method has the advantage of being implicit and of ensuring second order convergence in time. The spatial derivatives were discretized following a finite volume approach, ensuring the conservation of the amount of dust particles within the computational domain.

Table 2 summarizes the main input parameters required by our model to simulate dust dispersal during an erosion event. Simulations started with an air clean of dust. Saltating particles had a geometric mean diameter of $210 \mu \mathrm{m}$ and a geometric standard deviation of 1.8. Dust particle diameters ranged from 0.1 to $16 \mu \mathrm{m}$, divided into 15 log-normal bins.

In our simulation analysis, the time variations of dust concentration and dust flux profiles were converted into spatial variations from an upwind virtual border of an erodible surface, corresponding to $t=0 \mathrm{~s}$, to distances $x=U_{\text {int }} t$, referring to the fetch length, where $U_{\text {int }}$ is the integral wind speed $\left(U_{\text {int }}=\int_{0}^{z_{\text {ref }}} u(z) d z / z_{\text {ref }}\right.$, where $z_{\text {ref }}$ was chosen equal to the height of the investigated dust flux, $3 \mathrm{~m}$ here, unless otherwise specified). This time-space conversion allows us to evaluate the sensitivity of the dust flux PSD to the deposition process according to the fetch length. 


\section{Model evaluation}

Before using our model to investigate the sensitivity of the near-surface dust flux PSD, we find it important to evaluate its ability to reproduce published dust flux behaviors.

\subsection{Dust flux versus wind intensity compared to existing dust emission schemes}

Existing dust emission schemes show a clear increase of the dust flux with increasing wind intensity. Here, our model was used to simulate 15-minute erosion events (fetch up to $20 \mathrm{~km}$ ) with different stationary wind intensities $\left(u_{*}\right)$, starting with an air clean of dust. The surface dust size distribution $\left(p_{d}\right)$ was considered enriched in small particles (D1 distribution in Fig. 3). The cohesive bond exponent $\beta$ was set to 2 . This combination of $\beta=2$ and distribution D1 leads to an equiprobable PSD of emitted dust. The dust emission coefficient $(\alpha)$ that modulates the amplitude of the dust flux in our model (Eq. 13), was chosen so as the simulated dust flux at $u_{*}=0.40 \mathrm{~ms}^{-1}$ fits the one from Shao et al.'s (1993) scheme.

The 3-m high $F_{w c, t o t}$, including all particle sizes, as simulated by our model after 15 -minute erosion, exhibits a similar trend with $u_{*}$ as the fluxes obtained from the emission schemes of Shao et al. (1993) and Marticorena and Bergametti (1995) (Fig. 4). This agreement confirms the accurate sensitivity to the wind intensity of the magnitude of the dust flux simulated by our model. The same was verified for different combinations of $\beta$ and $p_{d}$ by fitting different values of $\alpha$.

\subsection{Dust concentration vertical profile compared to analytical solution}

At steady state over an extended homogenous surface $\left(F_{\text {emi, } b}=F_{d e p, b}\right)$, the conservation equation of dust concentration (Eq. 4) leads to the following analytical solution (Shao, 2008):

$$
c_{b}(z)=c_{b}\left(z_{r}\right)\left(z / z_{r}\right)^{v_{s, b} /\left(\kappa u_{*}\right)},
$$

where $z_{r}$ is a reference height.

The concentration profile simulated by our model at equilibrium between $F_{\text {emi,b }}$ and $F_{d e p, b}$ is consistent with this analytical solution (Fig. 5). This was verified for an erosion event with $u_{*}=0.40 \mathrm{~ms}^{-1}$ and $16.0 \mu \mathrm{m}$ dust particles, in a $35 \mathrm{~m}$ high domain. This equilibrium was reached for a fetch $x_{e q}=36 \mathrm{~km}$. With a larger domain, $x_{e q}$ increases as the emitted dust particles have a larger volume to disperse, reducing the near-surface dust concentration, and thus the deposition. For typical surface atmospheric boundary layer of $200 \mathrm{~m} \mathrm{high,} x_{e q} \approx 200 \mathrm{~km}$. The equilibrium fetch also increases with decreasing particle size. For 5 and $10 \mu \mathrm{m}$ dust particles and a $200 \mathrm{~m}$ high domain, $x_{e q} \approx 320$ and $640 \mathrm{~km}$, respectively. Simulations with particles smaller than $5 \mu \mathrm{m}$ led to an equilibrium fetch larger than a few thousand kilometers.

\subsection{Dust flux enrichment in small particles compared to Dupont et al. (2015) large-eddy simu- lation}

Dupont et al. (2015) performed detailed three-dimensional simulations of soil erosion of a bare surface by representing the main erosion processes (saltation, sandblasting, dust suspension) within a large-eddy simulation (LES) airflow model that simulated instantaneous wind. They simulated 20-minute long erosion events, with three dust particle bins 1.5, 6.7, 14.2 $\mu \mathrm{m}$, under three wind conditions $\left(u_{*}=0.47,0.63,0.77 \mathrm{~ms}^{-1}\right)$. By assuming an equiprobable emission of the three size bins, they observed an enrichment of the 2-m high $F_{w c}$ in small particles with time. This enrichment was explained by the nonstationarity of the erosion process, due to the lower 
deposition velocity of the smaller dust particles. Here, we reproduced these simulations with our simple 1D model using similar erosion configurations as in Dupont et al. (2015).

Fig. 6 presents the time variation of the fractions in number of $F_{w c, b}$ on $F_{w c, t o t}$, for the three size bins and three wind intensities, as estimated from our model and compared to Dupont et al. (2015). Our 1D model reproduces quite efficiently the flux enrichment in the smallest bin (1.5 $\mu \mathrm{m})$ and the impoverishment in $6.7 \mu \mathrm{m}$ particles with time and with increasing wind intensities. The small differences between both models may be explained by the difference in modelling the turbulence in the saltation layer between both approaches.

\subsection{Dust flux PSD compared to Alfaro et al. (1997) wind-tunnel experiment}

Alfaro et al. (1997) observed from a wind-tunnel experiment an enhancement of the emission of small dust particles with increasing wind intensity. This was observed from the mass size distribution of dust accumulated in a horizontal trap above the surface during a certain period (not specified by the authors). This led them to suggest the enrichment of the emitted dust in small particles with increasing wind intensity and to propose a time-independent dust emission scheme, equivalent to $\beta=-0.018$. Later, Shao (2001) validated his dust emission scheme by reproducing similar time-independent PSD of the dust flux as a function of the wind intensity. To obtain his result, he chose $\beta=2$ with a different surface dust size distribution than Alfaro et al. (1997).

Here, our 1D model is used to reproduce the Alfaro et al. (1997) experiment by simulating erosion events in a domain with the same vertical size $(70 \mathrm{~cm})$ as their wind tunnel. The interparticle cohesive bond exponent $\beta$ was set to -0.018 and the surface dust size distribution (Fig. 3) was chosen so as the $F_{\text {emi }}$ PSD for $u_{*}=0.40 \mathrm{~ms}^{-1}$ equates that observed by Alfaro et al. (1997). Two simulations were conducted: one where $F_{\text {emi }}$ PSD exhibited no dependence to the wind intensity $\left(\zeta\left(d_{b}, u_{*}\right)=1\right.$ in Equation 14), and the other one where $F_{\text {emi }}$ PSD followed the dependence to the wind intensity proposed by Alfaro et al. (1997) $\left(\zeta\left(d_{b}, u_{*}\right) \neq 1\right)$.

Fig. 7 compares the mass size distributions of $F_{w c}$ simulated by the current model and observed by Alfaro et al. (1997), for a 5-m long fetch and three friction velocities. For $u_{*}=$ $0.40 \mathrm{~ms}^{-1}$, our model agrees with the observations of Alfaro et al. (1997) regardless of $\zeta\left(d_{b}\right)$. At higher wind speeds, our results only agree with Alfaro et al.'s ones when $F_{\text {emi }}$ PSD is a function of the wind speed $\left(\zeta\left(d_{b}, u_{*}\right) \neq 1\right)$. This result implies a negligible effect of deposition, sedimentation and turbulence, in shaping the PSD of the near-surface dust flux and, thus, in differentiating the PSDs of $F_{w c}$ and $F_{e m i}$, for the conditions of the wind tunnel experiment. This result leaves open the possibility of the dust flux enrichment in small dust particles with wind intensity due to an enhancement of aggregate disintegration (Alfaro et al., 1997).

\subsection{Dust flux PSD compared to Kok (2011b) parametrization}

Kok (2011b) proposed a PSD of emitted dust independent of the soil granulometry and wind intensity. They based their proposition on several field data measured at a few meters above the surface and under various fetch magnitudes, ranging from $200 \mathrm{~m}$ to $10 \mathrm{~km}$. Here, our model is used to simulate erosion events corresponding to a maximum fetch of $10-\mathrm{km}$ with three wind conditions $\left(u_{*}\right), \beta=2$, and the surface dust size distribution proposed by Kok (2011b) (Fig. 3). The 3-m high $F_{w c}$ PSD in number simulated by our model (Fig. 8a) is close to that of Kok (2011b) for small fetch lengths $(<5 \mathrm{~m})$. As the fetch increases, the fraction of the largest particles in the dust flux decreases due to their surface deposition, and thus the flux enriches in small particles. This enrichment in small particles (impoverishment in large particles) is accentuated 
with $u_{*}$ as the deposition velocity increases (Fig. 2). The differences between the simulated nearsurface dust flux PSD and the emitted flux PSD proposed by Kok (2011b) are amplified when the PSDs are expressed in mass as it emphasizes the role of the largest particles (Fig. 8b).

\section{Sensitivity of the dust flux PSD}

To investigate the sensitivity of $F_{w c}$ PSD, 10 simulations were conducted varying either (1) the inter-particle cohesive bond exponent $(\beta),(2)$ the surface dust-size distribution $\left(p_{d}\right)$, or (3) the wind intensity $\left(u_{*}\right)$. Each simulation started from an air clean of dust. This sensitivity of $F_{w c}$ PSD is presented according to the fetch size, with values ranging from $5 \mathrm{~m}$ to $10 \mathrm{~km}$. To focus solely on the possible impact of the deposition process on $F_{w c}$ PSD, the $F_{\text {emi }}$ PSDs were considered independent of the wind intensity, i.e. $\zeta\left(d_{b}, u_{*}\right)=1$ in Equation 14.

Table 3 summarizes the range of each parameter-forcing considered in this analysis. For $p_{d}$, four surface dust-size distributions (D1, D2, D3 and D4) were considered (Fig. 3). They were chosen so as to obtain for $\beta=2$ the following $F_{\text {emi }}$ PSDs (Fig. 9d): equinumber emissions across bins (D1), strong emission around $0.7 \mu \mathrm{m}$ corresponding to particles with the lowest deposition velocity (D2), two emission peaks at 0.7 and $8 \mu \mathrm{m}$ (D3), and strong emission around $8 \mu \mathrm{m}$ corresponding to particles with large deposition velocity (D4). Fig. 9 presents the $F_{\text {emi }}$ PSDs obtained for the different combinations of $\beta$ and $p_{d}$ considered in our analysis. These PSDs cover the usual distributions encountered in existing emission schemes (Alfaro and Gomes, 2001; Shao, 2001; Kok et al., 2014).

The variation of the 3-m high $F_{w c}$ PSDs is presented in number in Fig. 10 according to the fetch size. Fig. 10 includes results for (a) three wind conditions $\left(u_{*}=0.30,0.40\right.$ and $\left.0.50 \mathrm{~ms}^{-1}\right)$ with $\beta=2$ and the surface dust-size distribution D1, (b) three surface dust-size distributions (D2, D3 and D4) with $\beta=2$ and $u_{*}=0.40 \mathrm{~ms}^{-1}$, and (c) four surface cohesive bond exponents $(\beta=$ $-1,0,1$ and 3 ) with the surface dust-size distribution D1 and $u_{*}=0.40 \mathrm{~ms}^{-1}$. Additionally, Fig. 11 presents the fraction in number and in mass of $F_{w c}$ partitioned in four bins (Z1 to Z4) on the total dust flux $F_{w c, t o t}$, according to the fetch size. Here, these four bins cover the whole dust size range. They were defined based on the variations of the particle deposition velocity with the particle size (Fig. 2) such as Z1 bin $(<0.3 \mu \mathrm{m})$ covers the region of predominant brownian deposition, Z2 bin $(0.3-1.0 \mu \mathrm{m})$ covers the region of minimum deposition velocity, $\mathrm{Z} 3$ bin $(1.0-8.0 \mu \mathrm{m})$ covers the region of sharp rise in deposition velocity, and $\mathrm{Z} 4$ bin $(>8.0 \mu \mathrm{m})$ covers the region of predominant gravitational settling.

An enrichment of $F_{w c}$ in particles with the lowest deposition velocity (Z2 bin) is observed with the fetch when the emitted dust at the surface $\left(F_{\text {emi }}\right)$ is deprived in dust from the $\mathrm{Z} 2$ bin (Fig.10a; D3, D4 in Fig. 10b; $\beta=0,1$ in Fig. 10c). This enrichment slightly extents to particles of the Z1 bin (Fig.11a; D3, D4 in Fig. $11 \mathrm{~b} ; \beta=0,1$ in Fig. 11c), and implies an impoverishment in particles from $\mathrm{Z} 3$ and $\mathrm{Z} 4$ bins. When $F_{\text {emi }}$ is dominated by particles of the $\mathrm{Z} 2 \mathrm{bin}$, no enrichment (impoverishment) is observed as $F_{\text {emi }}$ is already dominated by particles the least likely to deposit (D2 in Figs. 10b, $11 \mathrm{~b}$ and $\beta=3$ in Figs. 10c, 11c).

The resulting difference from this enrichment between $F_{w c}$ and $F_{e m i}$ PSDs represents a few percent of the flux for fetch lengths around $100 \mathrm{~m}$, but can rise to about $10 \%$ for fetch longer than $1 \mathrm{~km}$ (Fig. 11). These percentages are observed for fluxes expressed either in number or in mass. This modification of $F_{w c}$ PSD with the fetch occurs mainly within the first few hundred meters from the upwind border of the source area, then it evolves slowly with the fetch (Fig. 10a). This is visible, for example, in the simulation with the D1 surface PSD and $u_{*}=0.50 \mathrm{~ms}^{-1}$ (Fig. 11a) 
where the fraction of $F_{w c}$ from bins Z3 and Z4 decreases by nearly $5 \%$ within the first $200 \mathrm{~m}$, followed by only a $2 \%$ decrease up to $10 \mathrm{~km}$.

The enrichment of $F_{w c}$ in particles of the $\mathrm{Z} 2$ bin is accentuated with the wind speed (Figs. 10a and 11a). For a D1 surface PSD and $\beta=2$, the fraction of $F_{w c}$ from bin Z2 increases by about $2 \%$ at a fetch around $100 \mathrm{~m}$ between $u_{*}=0.30$ and $0.50 \mathrm{~ms}^{-1}$, and by about $5 \%$ at fetch longer than $1 \mathrm{~km}$ (Fig. 11a). In a different way, for $u_{*}=0.50 \mathrm{~ms}^{-1}, F_{w c}$ from bin Z2 already reaches in number $39 \%$ of the total $F_{w c}$ for a fetch of $100 \mathrm{~m}$ while a fetch of $10 \mathrm{~km}$ is needed to reach the same fraction for $u_{*}=0.30 \mathrm{~ms}^{-1}$ (Fig. 11a). Furthermore, the particle size below which such enrichment occurs decreases from $5 \mu \mathrm{m}$ to $3 \mu \mathrm{m}$ (Fig. 10a) when $u_{*}$ increases from 0.30 to $0.50 \mathrm{~ms}^{-1}$, emphasizing the role of the wind speed in shaping $F_{w c}$ PSD through its impact on the deposition velocity.

The strength of $F_{w c}$ enrichment in small particles depends on the $F_{e m i}$ PSD. This latter one is shaped by the combination of the surface PSD and the inter-particle cohesive bond exponent $(\beta)$ (Fig. 9), $\beta$ controlling the difference in PSD between the dust available at the surface and the dust emitted from the surface. Regardless of the surface PSD, a high positive value of $\beta(\approx 3)$ results in a strong emission of the smallest particles, and conversely a strong emission of the largest particles occurs for a small value of $\beta(\approx-1)$ (Figs. 10c and 11c). The enrichment of $F_{w c}$ in dust of the $\mathrm{Z} 2$ bin is minimal for these extreme cases due to either the insignificant concentration of small particles $(\beta \approx-1)$ or the predominant concentration of particles of the Z1-Z2 bins $(\beta \approx 3)$ (Fig. 10c).

\section{Discussion and conclusion}

The particle size distribution (PSD) of the near-surface dust flux $\left(F_{w c}\right)$ was found to be mainly influenced by both the deposition process and the size distribution of the emitted dust $\left(F_{\text {emi }}\right)$.

The $F_{\text {emi }}$ PSD appeared shaped from the mutual choice of the size distribution of available dust at the surface $\left(p_{d}\right)$ and the inter-particle cohesive bond exponent $(\beta)$ (Fig. 9). Different combinations of both quantities can lead to the same $F_{\text {emi }}$ PSD. This explains why Shao (2001) and Alfaro and Gomes (2001) were able to reproduce from their schemes the $F_{w c}$ PSD observed by Alfaro et al. (1997) while using different values of $\beta, 2$ and -0.018 , respectively, and different surface dust size distributions (Fig. 3). Hence, the uncertainty of both quantities in existing dust emission schemes can be simply resolved by defining directly the $F_{\text {emi }}$ PSD. Defining $F_{\text {emi }}$ PSD becomes, however, all the more complex if $p_{d}$ is wind speed dependent as suggested by Alfaro et al. (1997).

For constant wind and dust emission conditions, our simulations suggested a distinction between the PSDs of $F_{e m i}$ and $F_{w c}$. This PSD difference increases with the length of the fetch, i.e. the distance from the upwind border of the source area. A difference of a few percent in the flux fraction in number of small dust particles $(0.3$ to $1 \mu \mathrm{m})$ between $F_{e m i}$ and $F_{w c}$ PSDs is observed for 100-m long fetch (Fig. 11). This difference can rise to $10 \%$ for fetch longer than $1 \mathrm{~km}$. In mass, this difference affects rather larger particles $(>1 \mu \mathrm{m})$. This modification of $F_{e m i}$ and $F_{w c}$ PSDs is explained by the deposition process, as previously found by Dupont et al. (2015) from LES. The deposition of dust particles slowly increases with the fetch as the concentration of dust in the air is enhanced. This process is particle size dependent due to the dependence of the deposition velocity on the particle size (Fig. 2).

Theoretically, the dust deposition should increase with the fetch until an equilibrium is reached between deposition and emission (stationary state). Our simulations showed that this 
steady state occurs for fetch lengths larger than a few thousand kilometers for particles lower than $5 \mu \mathrm{m}$ (section 3.2). This suggests a low probability of reaching a dust steady state during an erosion event. However, this result was obtained for an air clean of dust at the beginning of the simulation, i.e. a clean air upwind from the source area. For a background air already charged in dust particles passing through a source area, the deposition is expected to be larger and the equilibrium between deposition and emission should be reached for smaller fetch lengths. In that configuration of a background dust concentration, the magnitude of the difference in PSD between $F_{e m i}$ and $F_{w c}$ should be larger than that observed from our simulations.

Emission and deposition appeared in our simulations as parallel inseparable processes, the impact of the deposition on the $F_{w c}$ PSD being already visible (a few percent) for short fetch around $100 \mathrm{~m}$ (Fig. 11). These parallel emission and deposition processes may question the evaluation of existing dust emission schemes. As mentioned in the introduction, these schemes simulate the PSD of emitted dust at the surface $\left(F_{\text {emi }}\right)$ but have been usually evaluated against measurements performed well above the surface $\left(F_{w c}\right)$ where deposition should probably have started to sort particles. Since dust emission schemes do not account for deposition, it was assumed that the PSD of $F_{e m i}$ is identical to that of $F_{w c}$, and time-space independent for stationary wind conditions. Our results suggest that this evaluation procedure is not appropriate when comparing with field experiments, for which fetch lengths usually range from $100 \mathrm{~m}$ to several kilometers. However, the small fetch length of wind-tunnel experiments may ensure a PSD similarity between near-surface and surface emitted dust fluxes, as shown in our simulation of the wind-tunnel experiment of Alfaro et al. (1997) (section 3.4).

The wind intensity modifies the $F_{w c}$ PSD by increasing the surface deposition, especially for large particles (Fig. 2), and thereby accelerating the attainment of equilibrium between emission and deposition. A rise of the friction velocity $\left(u_{*}\right)$ from 0.30 to $0.50 \mathrm{~ms}^{-1}$ leads to a $10 \%$ increase (decrease) of the dust flux fraction of small (large) particles for 1-km long fetch (Fig. 11a). Hence, an observed enrichment of $F_{w c}$ in small particles with wind intensity could be explained by the enhancement of the deposition of larger particles for fetch lengths larger than $100 \mathrm{~m}$, adding to the higher release of small dust through a stronger disintegration of aggregates as proposed by Alfaro et al. (1997).

The magnitude of the difference between $F_{e m i}$ and $F_{w c}$ PSDs depends also on the difference in diameter between the particles the most emitted at the surface and the particles with the lowest deposition velocity (around $0.7-2.0 \mu \mathrm{m}$ following Fig. 2). The farther the peak of $F_{\text {emi }}$ PSD is from the minima of the deposition velocity, the greater is the difference in PSDs between $F_{w c}$ and $F_{\text {emi }}$ (Fig. 10b,c). Again, this is explained by the dependence of the deposition velocity to the particle size. The near-surface dust flux enriches in particles with the lowest deposition velocity. For $F_{\text {emi }}$ dominated by particles with the lowest deposition velocity, the PSDs between $F_{\text {emi }}$ and $F_{w c}$ remain similar regardless of the fetch (D2 in Fig. $10 \mathrm{~b}, \beta=3$ in Fig. 10c). This similarity in PSD does not mean an equilibrium between the emission and deposition processes (steady state).

In conclusion, the role of the deposition process when evaluating existing dust emission schemes against field experiments should be considered, especially for large fetch lengths and/or with a large-scale background dust concentration. Improving our prediction of the PSD of $F_{w c}$ requires not only a better understanding of the size distribution of $F_{\text {emi }}$ but also a better understanding of the deposition velocity according to the particle size. This is all the more complex as both, emission and deposition processes, are difficult to disentangle in experiments. 


\section{References}

Alfaro, S.C., Gaudichet, A., Gomes, L., Maillé, M., 1997. Modeling the size distribution of a soil aerosol produced by sandblasting. J. Geophys. Res. 102, 11239-11249.

Alfaro, S.C., Gomes, L., 2001. Modeling mineral aerosol production by wind erosion: Emission intensities and aerosol size distributions in source areas. J. Geophys. Res. 106, 18075-18084.

Ammi, M., Oger, L., Beladjine, D., A, V., 2009. Three-dimensional analysis of the collision process of a bead on a granular packing. Phys. Rev. E. 79, 021305, 1-9.

Anderson, R.S., Hallet, B., 1986. Sediment transport by wind: Toward a general model. GSA Bulletin 97, 523.

Claquin, T., Roelandt, C., Kohfeld, K., Harrison, S., Tegen, I., Prentice, I., Balkanski, Y., Bergametti, G., Hansson, M., Mahowald, N., Rodhe, H., Schulz, M., 2003. Radiative forcing of climate by ice-age atmospheric dust. Clim. Dyn. 20, 193-202.

Crank, J., Nicolson, P., 1947. A practical method for numerical evaluation of solutions of partial differential equations of the heat conduction type, in: Proceedings of the Cambridge Philosophical Society, pp. 50-64.

Derbyshire, E., 2007. Natural minerogenic dust and human health. AMBIO 36, 73-77.

Dupont, S., Alfaro, S.C., Bergametti, G., Marticorena, B., 2015. Near-surface dust flux enrichment in small particles during erosion events. Geophys. Res. Lett. 42, 1992-2000. 2015 GL063116.

Fratini, G., Ciccioli, P., Febo, A., Forgione, A., Valentini, R., 2007. Size-segregated fluxes of mineral dust from a desert area of northern china by eddy covariance. Atmos Chem Phys 7, 2839-2854.

Gillette, D., 1977. Fine particulate emissions due to wind erosion. Trans. ASAE 20, $890-897$.

Gillette, D.A., Blifford Jr., I.H., Fenster, C.R., 1972. Measurements of aerosol size distributions and vertical fluxes of aerosols on land subject to wind erosion. J. Appl. Meteorol. 11, 977-987.

Gillies, J., Berkofsky, L., 2004. Eolian suspension above the saltation layer, the concentration profile. J Sed Res 74, 176-183.

Gomes, L., Rajot, J., Alfaro, S., Gaudichet, A., 2003. Validation of a dust production model from measurements performed in semi-arid agricultural areas of spain and niger. CATENA 52, $257-271$.

Greeley, R., Iversen, J., 1987. Wind as a Geological Process: On Earth, Mars, Venus and Titan. Cambridge Planetary Science Old, Cambridge University Press.

Knippertz, P., Stuut, J., 2014. Mineral Dust: A Key Player in the Earth System. Springer Netherlands.

Kok, J.F., 2011a. Does the size distribution of mineral dust aerosols depend on the wind speed at emission? Atmos. Chem. Phys. 11, 10149-10156.

Kok, J.F., 2011b. A scaling theory for the size distribution of emitted dust aerosols suggests climate models underestimate the size of the global dust cycle. Proc. Natl. Acad. Sci. 108, 1016-1021.

Kok, J.F., Mahowald, N.M., Fratini, G., Gillies, J.A., Ishizuka, M., Leys, J.F., Mikami, M., Park, M.S., Park, S.U., Van Pelt, R.S., Zobeck, T.M., 2014. An improved dust emission model - part 1: Model description and comparison against measurements. Atmos. Chem. Phys. 14, 13023-13041.

Kok, J.F., Parteli, E.J.R., Michaels, T.I., Bou Karam, D., 2012. The physics of wind-blown sand and dust. Rep. Prog. Phys. 75, 106901.

Mahowald, N., Samuel, A., Kok, J., Engelstaeder, S., Scanza, R., Ward, D.S., Flanner, M.G., 2014. The size distribution of desert dust aerosols and its impact on the earth system. Aeolian Research 15, 53- 71.

Marticorena, B., Bergametti, G., 1995. Modeling the atmospheric dust cycle: 1. design of a soil-derived dust emission scheme. J. Geophys. Res. Atmos. 100, 16415-16430.

Otto, S., de Reus, M., Trautmann, T., Thomas, A., Wendisch, M., Borrmann, S., 2007. Atmospheric radiative effects of an in situ measured saharan dust plume and the role of large particles. Atmos. Chem. Phys. 7, 4887-4903.

Raupach, M.R., 1991. Saltation layers, vegetation canopies and roughness lengths. Acta Mech.

Reid, J.S., Reid, E.A., Walker, A., Piketh, S., Cliff, S., Al Mandoos, A., Tsay, S.C., Eck, T.F., 2008. Dynamics of southwest asian dust particle size characteristics with implications for global dust research. J. Geophys. Res. Atmos. 113. D14212

Rice, M.A., Willets, B.B., McEwan, I.K., 1995. An experimental study of multiple grain-size ejecta produced by collisions of saltating grains with a flat bed. Sedimentology 42, 695-706.

Seinfeld, J., Pandis, S., 1998. Atmospheric chemistry and physics: from air pollution to climate change. A Wiley interscience publication, Wiley.

Shao, Y., 2001. A model for mineral dust emission. J. Geophys. Res. Atmos. 106, 20239-20254.

Shao, Y., 2008. Physics and Modelling of Wind Erosion. Atmospheric and Oceanographic Sciences Library, Springer Netherlands.

Shao, Y., Ishizuka, M., Mikami, M., Leys, J.F., 2011. Parameterization of size-resolved dust emission and validation with measurements. JGR Atm. 116.

Shao, Y., Lu, H., 2000. A simple expression for wind erosion threshold friction velocity. J. Geophys. Res. Atmos. 105, 22437-22443. 
Shao, Y., Raupach, M.R., F., L.J., 1996. A model for predicting aeolian sand drift and dust entrainment on scales from paddock to region. Soil Res. 34, 309-342.

Shao, Y., Raupach, M.R., Findlater, P.A., 1993. Effect of saltation bombardment on the entrainment of dust by wind. J. Geophys. Res. Atmos. 98, 12719-12726.

Sow, M., Alfaro, S.C., Rajot, J.L., Marticorena, B., 2009. Size resolved dust emission fluxes measured in niger during 3 dust storms of the amma experiment. Atmos. Chem. Phys. 9, 3881-3891.

Swap, R., Garstang, M., Greco, S., Talbot, R., Kallberg, P., 1992. Saharan dust in the amazon basin. TELLUS B 44, 133-149.

Weuve, J., Puett, R.C., Schwartz, J., Yanosky, J.D., Laden, F., Grodstein, F., 2012. Exposure to particulate air pollution and cognitive decline in older women. Arch. Intern. Med. 172, 219-227.

White, B.R., 1979. Soil transport by winds on mars. J. Geophys. Res. Solid Earth 84, 4643-4651.

Zobeck, T.M., Scott Van Pelt, R., 2006. Wind-induced dust generation and transport mechanics on a bare agricultural field. J. Hazard. Mater 132, $26-38$. 
Flux Nomenclature

\begin{tabular}{ll}
\hline Symbol & Description \\
\hline$F_{\text {emi }}$ & Dust emission flux at the surface \\
$F_{\text {dep }}$ & Dust deposition flux at the surface \\
$F_{w c}$ & Near-surface dust turbulent-diffusive flux \\
$F_{\text {sed }}$ & Dust gravitational settling flux \\
& \\
Indices & \\
$b$ & Dust particles from the bth bin \\
$t o t$ & All dust particle sizes \\
\hline
\end{tabular}

Table 1: Dust flux notation. 


\begin{tabular}{ll}
\hline Parameter & Symbol \\
\hline PSD of available dust at the surface & $p_{d}$ \\
PSD of saltating particles & $p_{s}$ \\
Dust emission coefficient modulating the number of emitted dust per saltator & $\alpha$ \\
Inter-particle cohesive bond exponent & $\beta$ \\
Function modifying $p_{d}$ according to the wind intensity & $\zeta_{d}$ \\
Particle density & $\rho_{p}$ \\
Surface roughness length & $\mathrm{z}_{0}$ \\
Wind friction velocity & $\mathrm{u}_{*}$ \\
Ambient air properties (temperature, density, kinematic viscosity) & $T, \rho_{a}, v$ \\
\hline
\end{tabular}

Table 2: Main input parameters of our 1D dust dispersal model. 


\begin{tabular}{ll}
\hline Parameter & Range of values \\
\hline Friction velocity $\left(u_{*}\right)$ & $0.30,0.40,0.50 \mathrm{~ms}^{-1}$ \\
PSD of available dust at the surface $\left(p_{d}\right)$ & $\mathrm{D} 1, \mathrm{D} 2, \mathrm{D} 3, \mathrm{D} 4(\mathrm{see}$, Fig. 3) \\
Inter-particle cohesive bond exponent $(\beta)$ & $-1,0,1,2,3$ \\
\hline
\end{tabular}

Table 3: Range of values of the parameters considered in our sensitivity analysis of the dust flux PSD. 


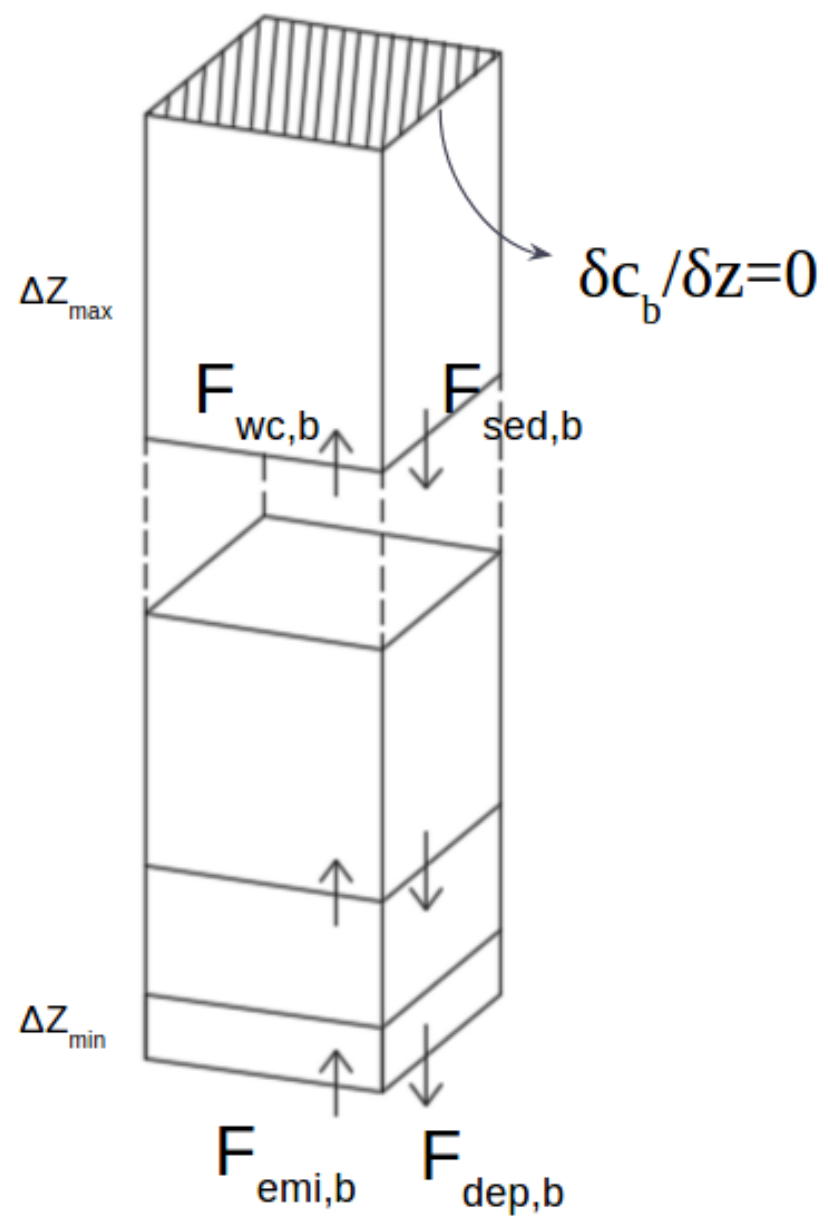

Figure 1: Schematic representation of the 1D computational domain used in this study. 


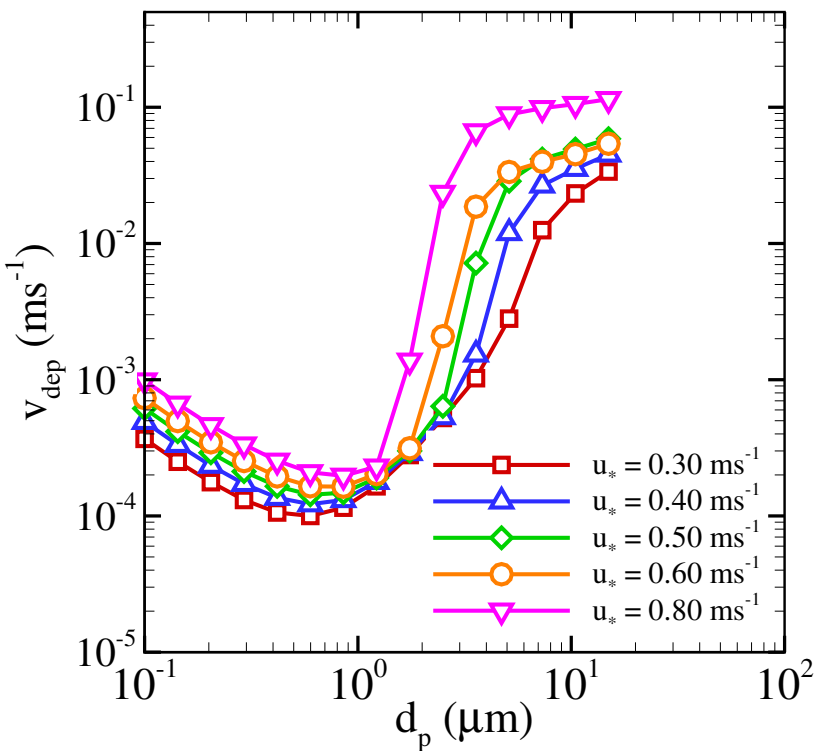

Figure 2: Variation of the deposition velocity $\left(v_{d e p}\right)$ with dust particle diameter $\left(d_{p}\right)$ for five wind intensities $\left(u_{*}=0.30,0.40,0.50,0.60\right.$ and $\left.0.80 \mathrm{~ms}^{-1}\right)$. 
(a)

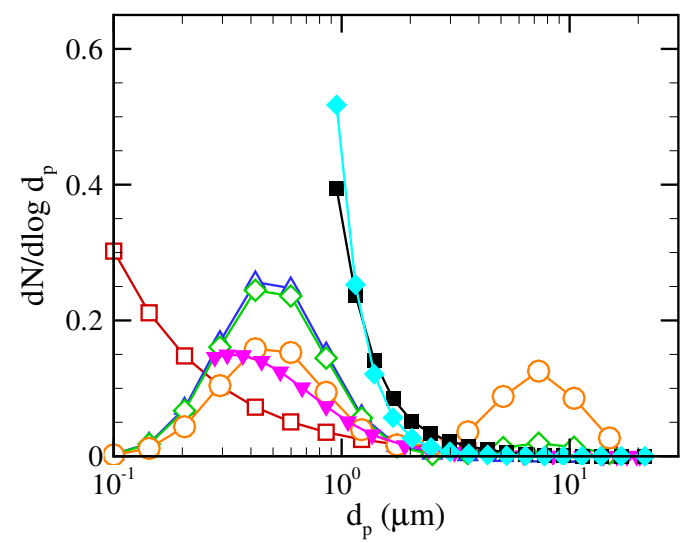

(b)

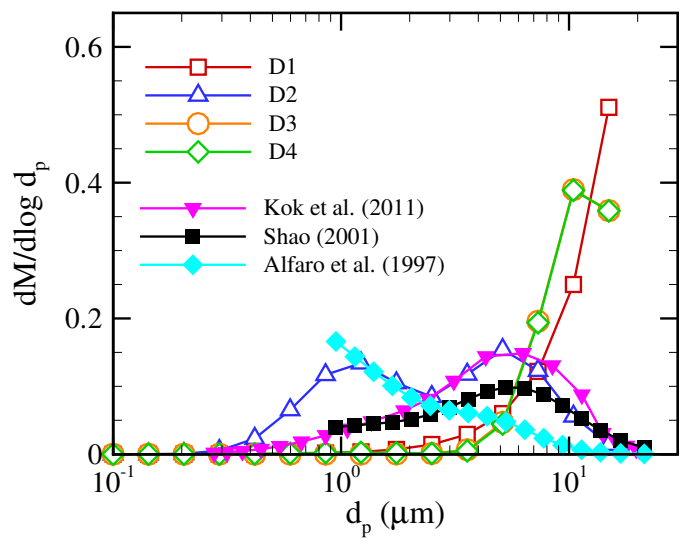

Figure 3: Size distributions in number (a) and in mass (b) of dust particles available at the surface considered in our simulations (D1, D2, D3 and D4) as well as reported in the wind-tunnel experiment of Alfaro et al. (1997) and used in Shao (2001) and Kok (2011a) numerical experiments. The choice of distributions D1 through D4 is explained in section 4. 


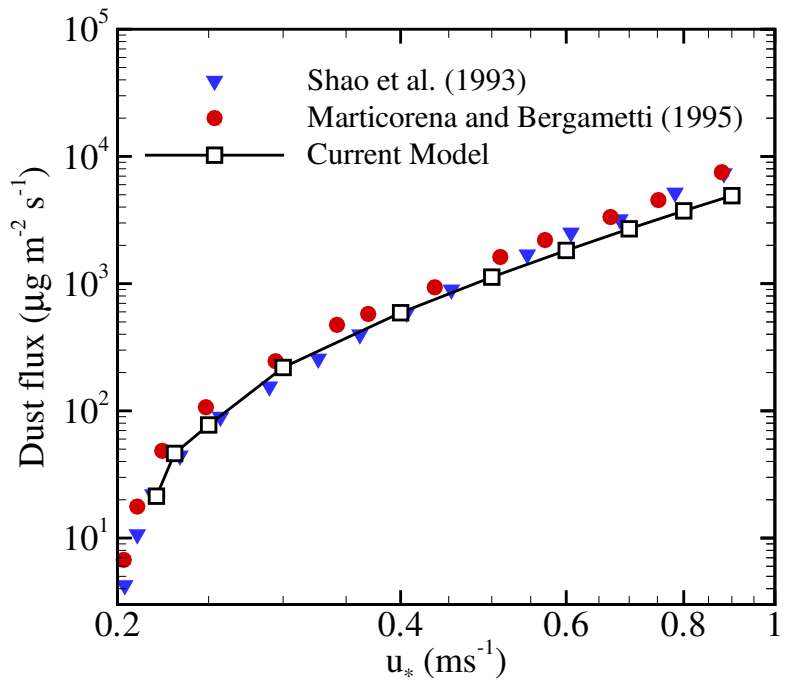

Figure 4: Vertical dust flux $\left(F_{w c, t o t}\right)$, including all particle sizes, as a function of the friction velocity $\left(u_{*}\right)$ obtained from our 1D model and compared with the empirical parametrizations of (1) Marticorena and Bergametti (1995): $F_{w c, t o t}=\gamma Q_{t o t}$, with $\gamma=10^{-2}$, and (2) Shao et al. (1993): $F_{w c, t o t}=$ $C \rho_{d}\left(u_{*}^{2}-u_{* t}^{2}\right)$, with $C=4$ and $u_{* t}=0.2 \mathrm{~ms}^{-1}$. Note that the dust emission coefficient $(\alpha)$ of our model (Eq. 13) was chosen so as $F_{w c, t o t}$ fits the value obtained from Shao et al. (1993) scheme at $u_{*}=0.40 \mathrm{~ms}^{-1}$ 


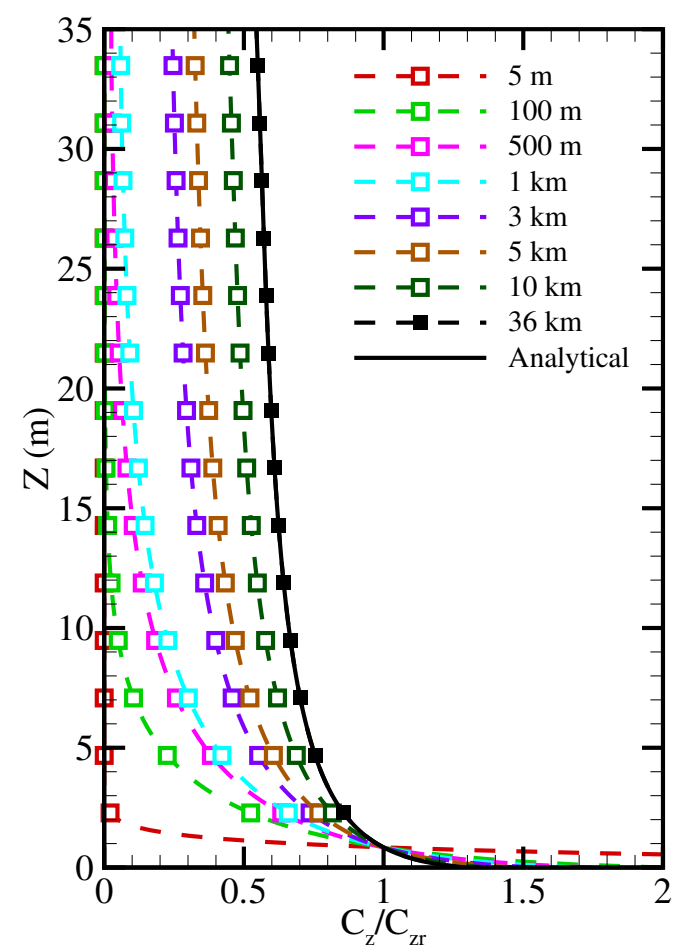

Figure 5: Variation with the fetch length of the simulated vertical dust concentration profiles (dot-lines) and comparison at steady state against the analytical profile (solid line) for $16 \mu \mathrm{m}$ dust particle in a $35 \mathrm{~m}$ high domain, and with $u_{*}=0.40 \mathrm{~ms}^{-1}$. The analytical profile responds to $c_{b}(z)=$ $c_{b}\left(z_{r}\right)\left(z / z_{r}\right)^{v_{s, b} /\left(\kappa u_{*}\right)}$, where $z_{r}$ is a reference height corresponding here to $1 \mathrm{~m}$. 

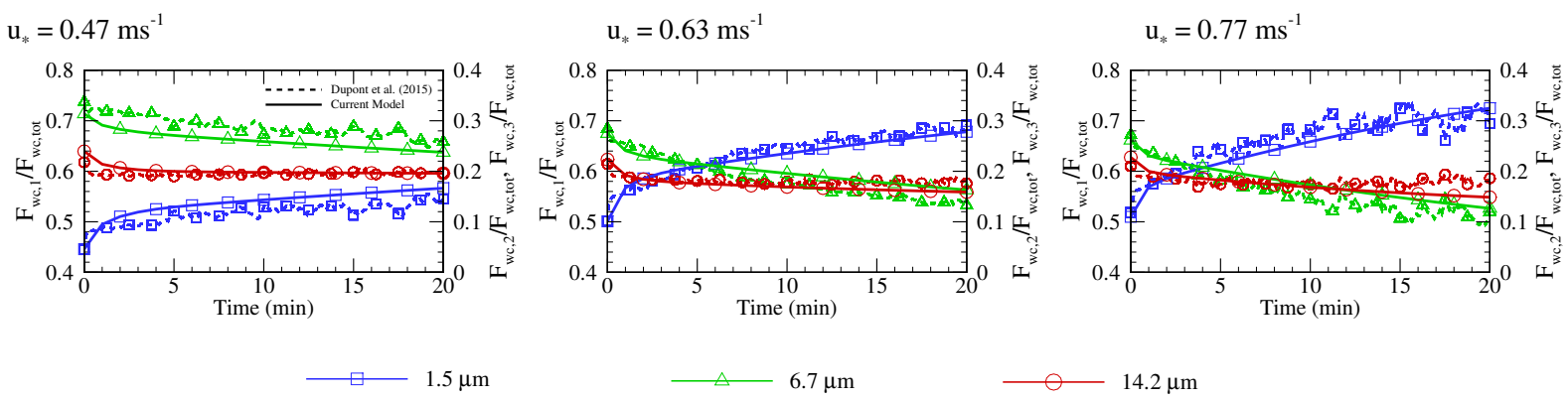

$14.2 \mu \mathrm{m}$

Figure 6: Time variation of the fraction in number of the turbulent-diffusive fluxes $\left(F_{w c, b}\right)$ at $2 \mathrm{~m}$ height of $1.5 \mu \mathrm{m}$ (blue, $\mathrm{b}=1$ ), $6.7 \mu \mathrm{m}$ (green, $\mathrm{b}=2$ ) and $14.2 \mu \mathrm{m}$ (red, $\mathrm{b}=3$ ) particle diameters, on the total turbulent-diffusive dust flux $F_{w c, t o t}$, for three wind conditions $\left(u_{*}\right)$ simulated by our model (solid lines) in comparison with those from Dupont et al. (2015) (dotted lines). 
$\mathrm{u}_{*}=0.40 \mathrm{~ms}^{-1}$

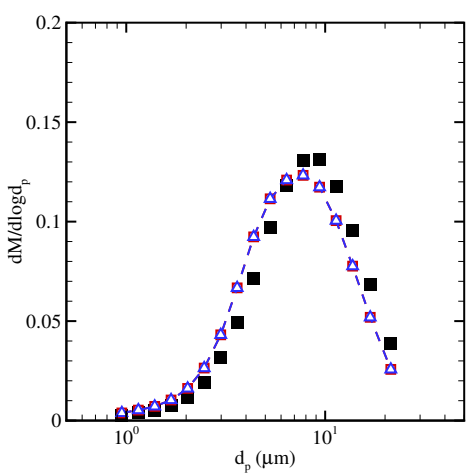

$\mathrm{u}_{*}=0.45 \mathrm{~ms}^{-1}$

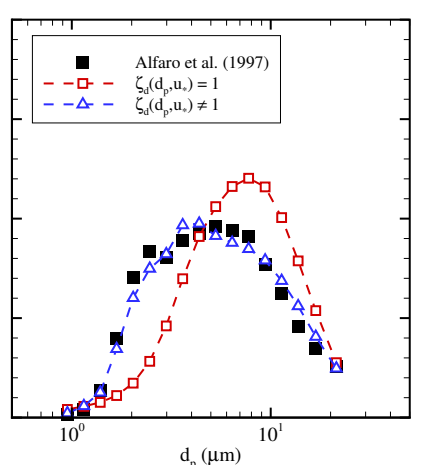

$\mathrm{u}_{*}=0.53 \mathrm{~ms}^{-1}$

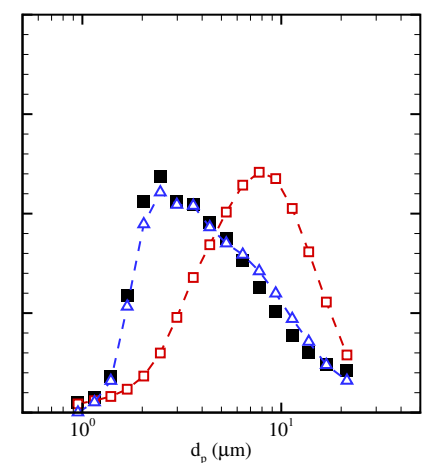

Figure 7: The mass size distribution of the vertical dust fluxes $\left(F_{w c}\right)$ as simulated by our model (line-dots) for three wind conditions $\left(u_{*}\right)$, and compared with the wind-tunnel observations from Alfaro et al. (1997) (filled squares). In one simulation, the PSD of available dust at the surface $\left(p_{d}\right)$ is independent of $u_{*}\left(\zeta_{d}=1\right)$ while in the other simulation $p_{d}$ depends on $u_{*}$ as suggested by Alfaro et al. (1997) $\left(\zeta_{d} \neq 1\right)$ 
(a) In number

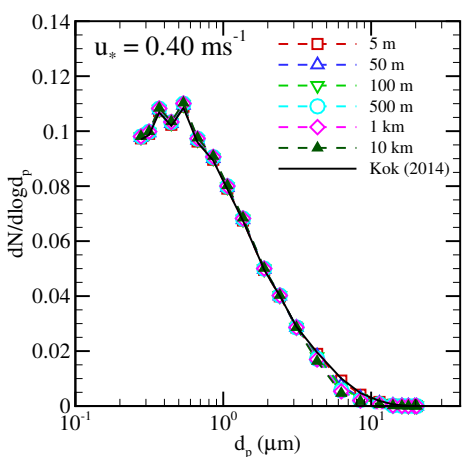

(b) In mass

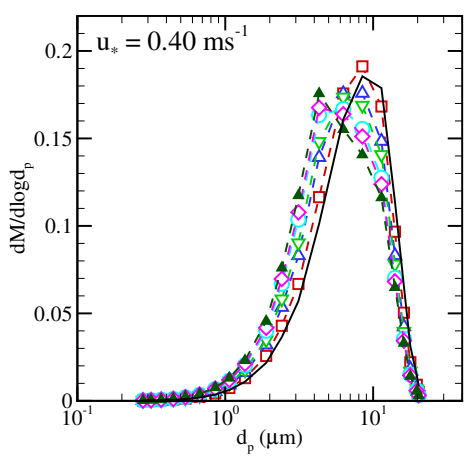

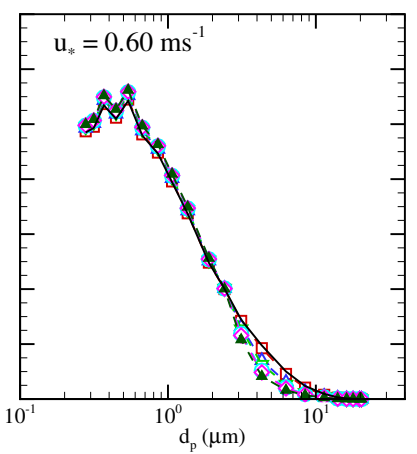
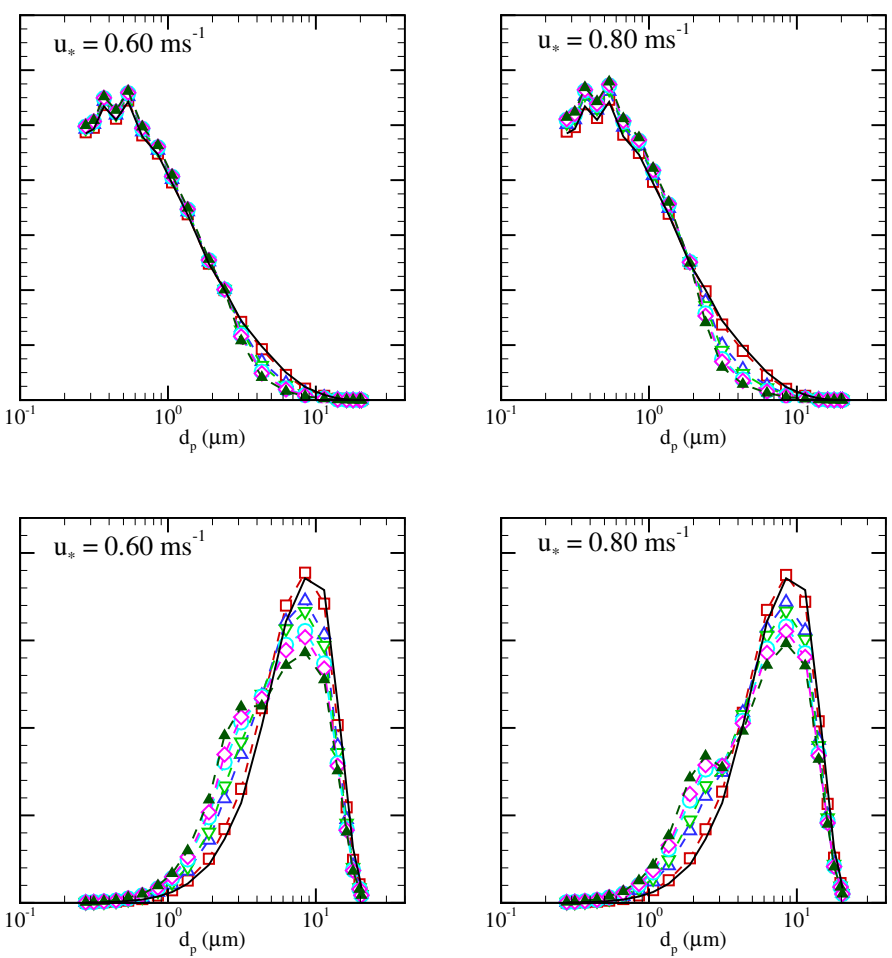

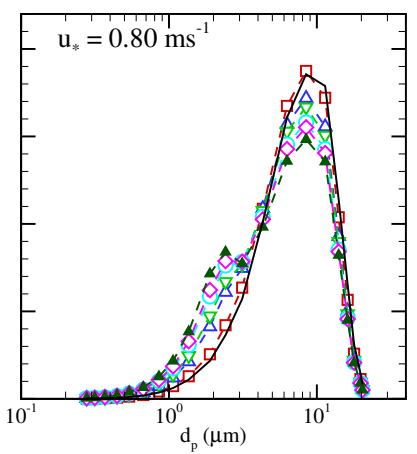

Figure 8: Variation with the fetch length of the size distribution in number (top row) and in mass (bottom row) of the 3-m high vertical dust fluxes $\left(F_{w c}\right)$ as simulated by our model (line-dots) for three wind conditions $\left(u_{*}\right)$ (line-dots), and compared with the prediction of Kok (2011b) (solid linefilled squares). The fetch ranges from $5 \mathrm{~m}$ to $10 \mathrm{~km}$. 
(a) Current Model with $\beta=-1$

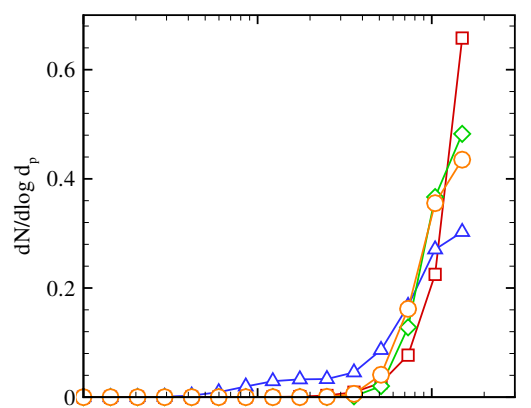

(c) Current Model with $\beta=1$

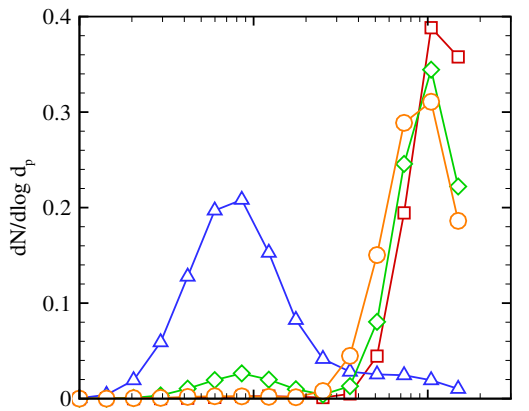

(e) Current Model with $\beta=3$

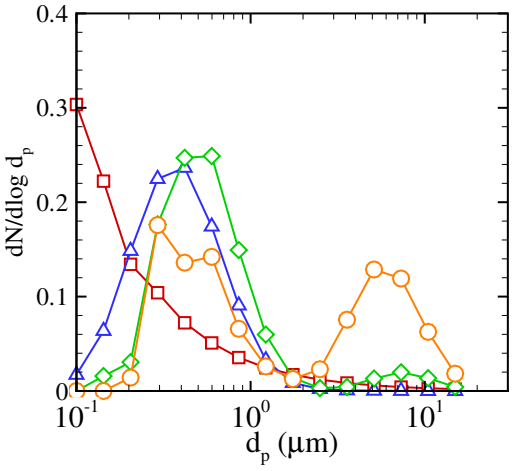

(b) Current Model with $\beta=0$

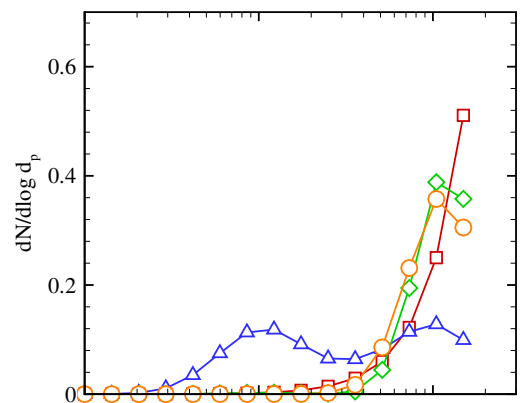

(d) Current Model with $\beta=2$
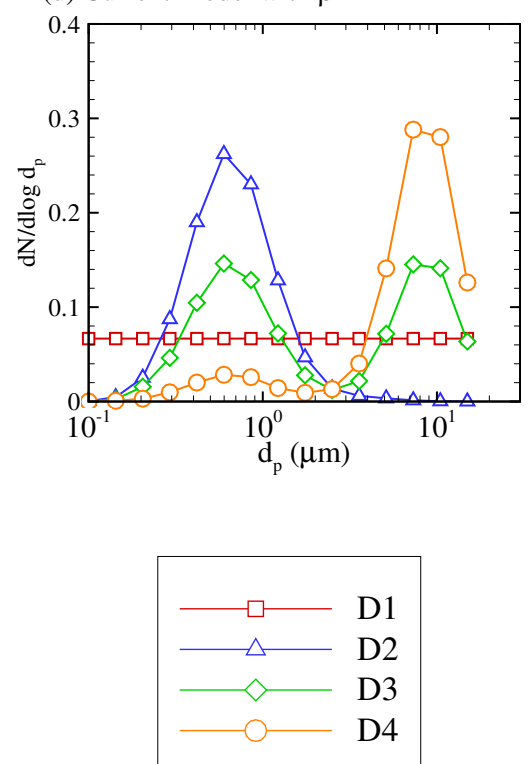

Figure 9: Size distributions in number of emitted dust at the surface $\left(F_{\text {emi }}\right)$ obtained from our model for various PSD of available dust at the surface (D1, D2, D3 and D4, see Fig. 3) and according to the inter-particle cohesive bond exponent $\beta$ (from -1 to +3 ) 

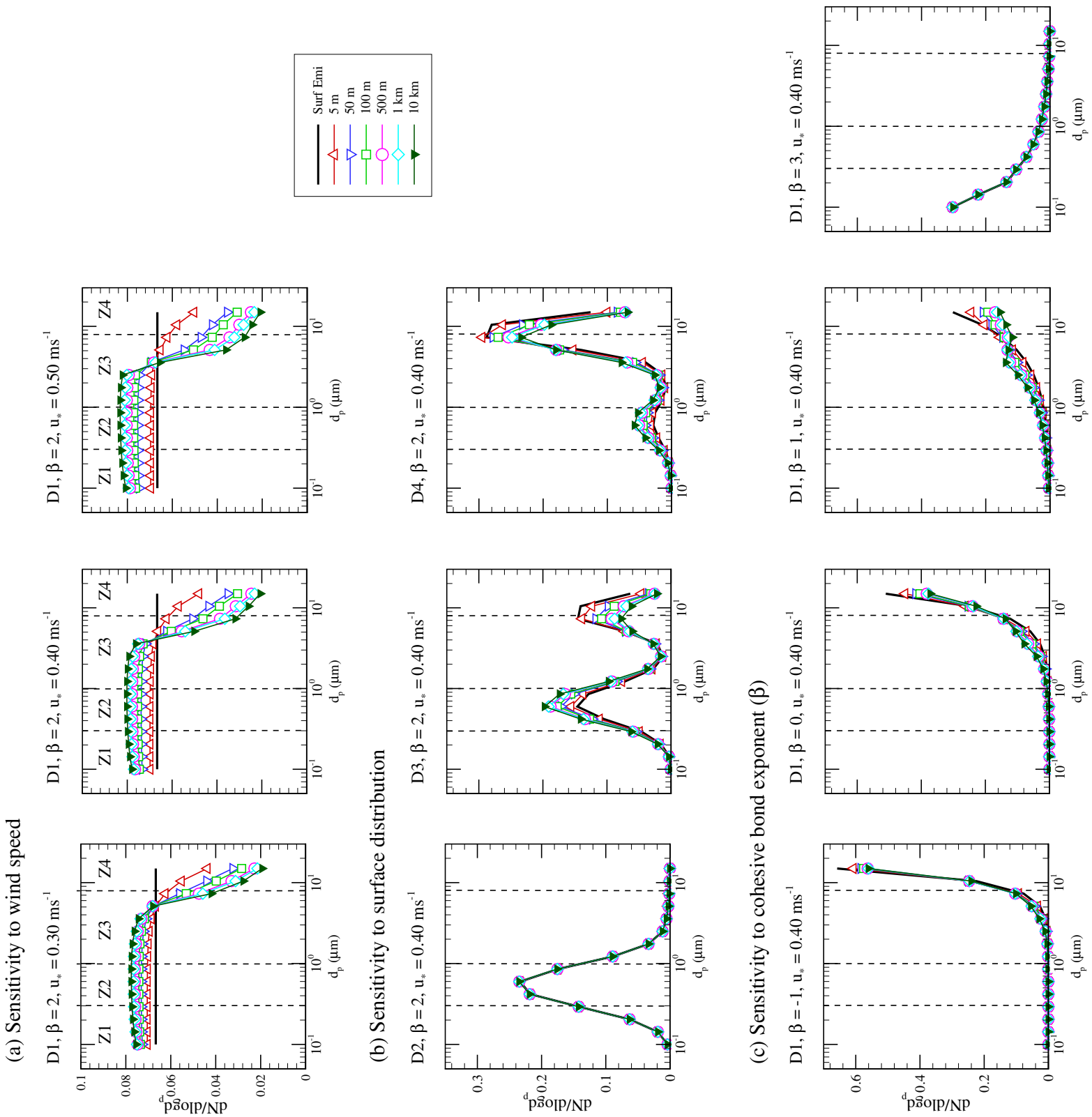

Figure 10: Variation with the fetch length of the size-distribution in number of the 3-m high $F_{w c}$ according to (a) the wind intensity $\left(u_{*}=0.30,0.40\right.$ and $\left.0.50 \mathrm{~ms}^{-1}\right)$, (b) the surface dust-size distributions (D2, D3 and D4, see Fig. 3), and (c) the inter-particle cohesive bond exponents $(\beta=-1,0,1$ and 3). The fetch ranges from $5 \mathrm{~m}$ to $10 \mathrm{~km}$. The dust particle range is divided into 4 bins: $\mathrm{Z} 1\left(d_{p} \leq\right.$ $0.3 \mu \mathrm{m})$ - particles with dominant brownian deposition, Z2 $\left(0.3 \mu \mathrm{m}<d_{p} \leq 2 \mu \mathrm{m}\right)$ - particles the least likely to deposit, Z3 $\left(2 \mu \mathrm{m}<d_{p} \leq 8 \mu \mathrm{m}\right)$ - particles with the deposition velocity the most sensitive to wind intensity, and Z4 $\left(d_{p}>8 \mu \mathrm{m}\right)$ - particles the most likely to deposit. 
(a) Sensitivity to wind speed (D1, $\beta=2)$
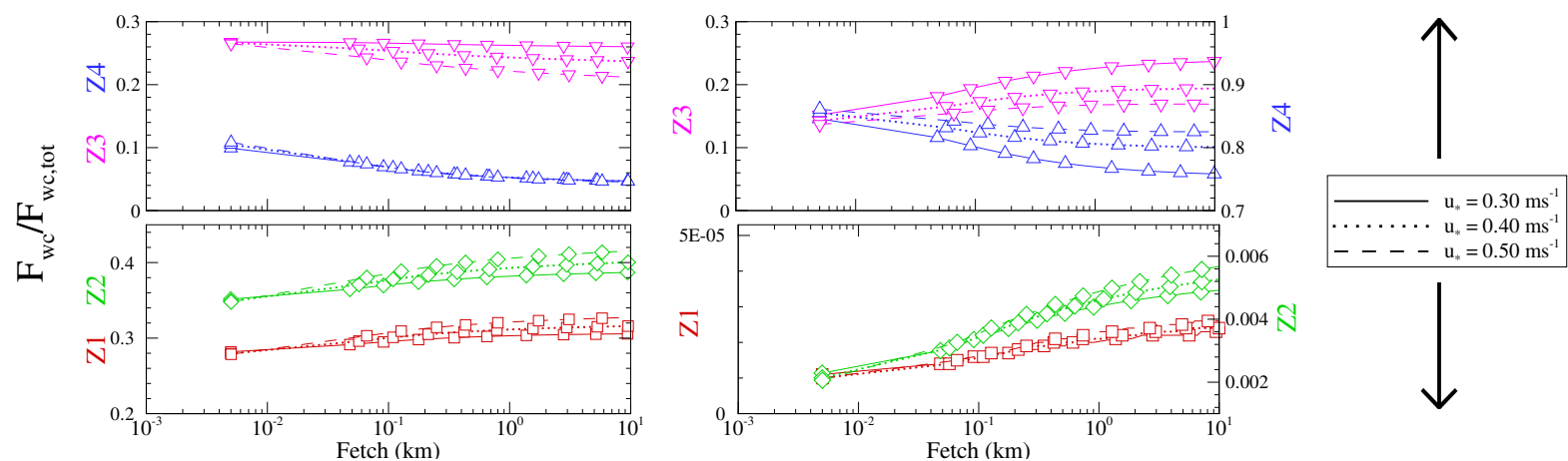

(b) Sensitivity to surface particle distribution $\left(\mathrm{u}_{*}=0.40 \mathrm{~ms}^{-1}, \beta=2\right)$
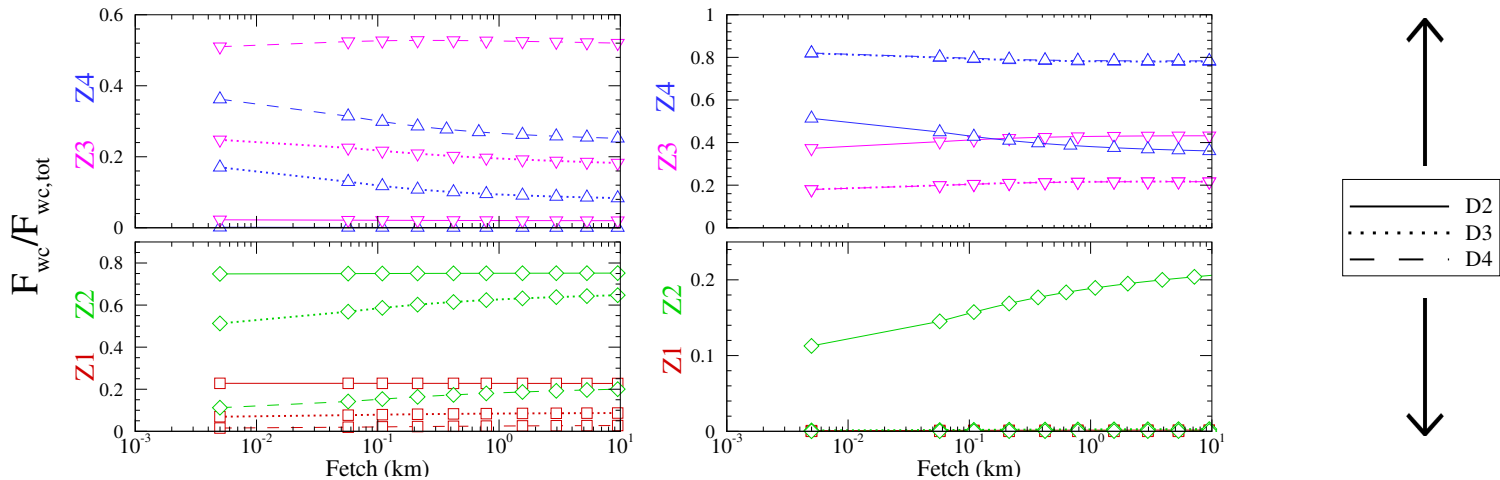

(c) Sensitivity to cohesive bond parameter $\left(\mathrm{u}_{*}=0.40 \mathrm{~ms}^{-1}, \mathrm{D} 1\right)$
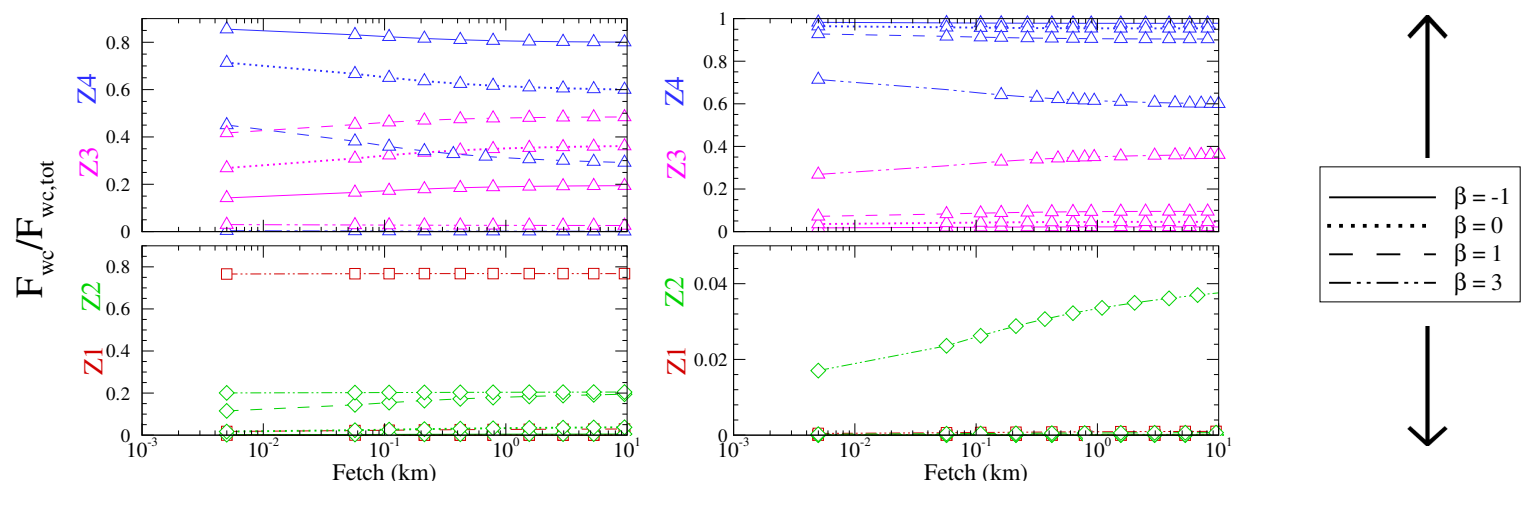

Figure 11: Variation with the fetch length of the fraction in number (left figures) and in mass (right figures) of the 3-m high $F_{w c}$ on the total turbulent-diffusive dust flux $F_{w c, t o t}$ according to (a) the wind intensity $\left(u_{*}=0.30,0.40\right.$ and $\left.0.50 \mathrm{~ms}^{-} 2\right)(\mathrm{b})$ the surface dust-size distributions (D2, D3 and D4, see Fig. 3), and (c) the inter-particle cohesive bond exponents $(\beta=-1,0,1$ and 3$) . F_{w c}$ is divided into 4 bins: $\mathrm{Z} 1\left(d_{p} \leq 0.3 \mu \mathrm{m}\right)$ - particles with dominant brownian deposition, $\mathrm{Z} 2(0.3$ $\left.\mu \mathrm{m}<d_{p} \leq 2 \mu \mathrm{m}\right)$ - particles the least likely to deposit, Z3 $\left(2 \mu \mathrm{m}<d_{p} \leq 8 \mu \mathrm{m}\right)$ - particles with the deposition velocity the most sensitive to wind intensity, and Z4 ( $\left.d_{p}>8 \mu \mathrm{m}\right)$ - particles the most likely to deposit. The fractions at the smallest fetch lengths are equivalent to those of the surface emitted dust flux $\left(F_{\text {emi }}\right)$. 